\title{
El concepto de "contexto" en las traducciones inglés- español: una aproximación sociolingüística a las competencias y decisiones del traductor
}

\author{
(The concept of "context" in English to Spanish translations: a \\ sociolinguistic approach to the translator's competence and decisions)
}

M.M. Rivas CARMONA (Universidad de Sevilla)

A. CARRANZA MÁRQUEZ (UNED, Madrid)

Fecha de recepción: 15 de febrero de 2010

Fecha de aceptación: 10 de abril de 2010

Resumen: El presente trabajo se inscribe en la tendencia actual de estudios interdisciplinares que analizan la interconexión entre factores culturales y discursivos. Gracias al 'giro pragmático' y el 'giro cultural' en los estudios traductológicos que comenzaran a gestarse en los años 70 la traducción pasó a entenderse como una "transferencia cultural" (Bassnett 1998). Por este motivo, es obvio que entre las competencias del traductor, además de la competencia comunicativa y textual en las lenguas y culturas origen y meta, es necesaria la competencia cultural y temática de los textos que ha de traducir.

Siguiendo un análisis tanto discursivo como traductológico, nuestro trabajo estudia dos textos extraídos de géneros tan diferentes como el literario y el subtitulado de películas originales de habla inglesa al español. En ambos textos se evidencia un desfase entre texto origen y texto meta que no cabe atribuir simplemente a deslices en el uso del español como instrumento comunicativo sino a fallos en la competencia cultural y temática por parte del traductor. Se trata, en suma, de que no se ha atendido al contexto específico ni cultural en la labor de traducción al español.

Palabras clave: Contexto. Competencia cultural. Variación dialectal. Variación funcional.

Abstract: This paper is in line with the present tendency within interdisciplinary studies which focuses on the relationship between cultural and discursive issues. Since the 'pragmatic turn' and the 'cultural turn' in translation studies which emerged in the 1970s, translation has been understood by many as a "cultural transfer" (Bassnett 1998). Therefore it seems quite obvious that, besides the 'communicative competence' and the 'textual competence' in both the original and target languages and cultures, the translator must be skilful at 'cultural competence' and 'thematic competence' of the texts that are to be translated. 
Following a discursive as well as a traductological analysis, we discuss two texts belonging to such different genres as literature and film subtitles from English into Spanish. In both of them the target texts are out of step with their corresponding original ones; this cannot be merely attributed to slips of tongue in the use of Spanish as a communicative instrument, but to translation failures in the translator's thematic and cultural competence. In sum, the case in point is that neither the immediate textual context nor the cultural context has been properly attended to in the translating process.

Key words: Context. Cultural competence. Dialectal variation. Functional variation.

\section{INTRODUCCIÓN}

El presente trabajo se inscribe dentro de la tendencia actual de los estudios interdisciplinares de 'análisis del discurso' y 'traducción'. Especialmente desde los años 90 se generalizaron en los Estudios de Traducción las perspectivas centradas en los conceptos de 'comunicación intercultural, 'cooperación interdisciplinar', 'interconexión entre factores culturales y discursivos' y 'relación directa entre uso lingüístico y contexto de producción y recepción'. Estos conceptos llevaban varias décadas desarrollándose en disciplinas como el Análisis del Discurso, la Pragmática o la Sociolingüística.

Como apunta Mary Snell-Hornby (2007:24), la aparición de la lingüística textual y la consideración de los aspectos funcionales, sociales y comunicativos del lenguaje había facilitado desde los años 70 un 'giro pragmático' en los Estudios de Traducción. Más allá de una mera operación lingüística, la traducción pasó a entenderse como una "transferencia cultural" con el llamado "giro cultural" (Bassnett 1998) de los estudios traductológicos. Es evidente que son muchas las competencias que debe poseer el traductor, especialmente la competencia comunicativa y textual en al menos dos lenguas y culturas y la competencia cultural y la temática en los campos que debe traducir.

Siguiendo un análisis tanto discursivo como traductológico, nuestro trabajo analiza textos extraídos de dos géneros tan diferentes como el literario y el subtitulado de películas originales de habla inglesa al español. En estos textos en particular se evidencia un desfase entre texto origen y texto meta que no cabe atribuir simplemente a deslices en el uso del español como instrumento comunicativo sino a fallos en la competencia cultural y temática por parte del traductor. Se trata, en suma, de que no se ha atendido al contexto específico ni cultural en la labor de traducción al español. 


\title{
1. LA TRADUCCIÓN, EL ANÁLISIS DEL DISCURSO Y EL CONCEPTO DE EQUIVALENCIA DINÁMICA
}

La traducción es una actividad que conlleva una comprensión completa de los textos. Para ello, a la hora de traducir no sólo tenemos que tomar en consideración la forma, el significado y los procesos por los que se interpreta, sino que es preciso saber qué tipo de texto tenemos ante nosotros. Para determinarlo debemos recurrir al "contexto":

\begin{abstract}
...When we translate we usually attempt to answer the straightforward question: which type of text are we translating? This means that the first thing we try to find out is what sort of general context serves as an overall frame on our translation. This is an all but unconscious move, because as soon as we begin to face a communicative act, we automatically search for all sources of information leading up to an efficient and relevant interpretation. (López and Badder 1999:3)
\end{abstract}

En otras palabras, al analizar el texto que tenemos que traducir no sólo debemos emplear nuestro conocimiento de la lengua y nuestra capacidad de entendimiento, sino que debemos contar también con las funciones de dicho discurso en su contexto, en la sociedad y en la cultura. Así lo expresaba T. van Dijk (1997:6):

Discourse should be studied not only as form, meaning and mental process, but also as complex structures and hierarchies of interaction and social practice and their functions in context, society and culture.

Está bien asumido, pues, que la traducción no consiste en un mero trasvase de palabras, en términos de Schulte (1987:2): "translation is not a mere transportation of words", muy al contrario, la traducción es quizá el fenómeno humano más complejo como apuntan críticos como I. A. Richards.

Cuando se trata de traducir enunciados pertenecientes a contextos específicos se hace especialmente relevante la necesidad de resaltar la distinción entre 'lenguaje' y 'discurso', ya señalada por Vinay y Darbelnet (1958): 'langue' vs. 'discours', en tanto que el lenguaje es un sistema objetivo de signos, externo al individuo, mientras el discurso es el lenguaje en uso en un contexto específico. Dicho de otro modo, en contextos específicos de traducción es particularmente necesario acudir al concepto de discurso (lenguaje en uso en un contexto concreto).

Cuando estamos buscando una "equivalencia" a la hora de traducir, no pensamos en 'unidades de traducción', sino en la situación concreta o específica en la que se ha emitido el enunciado. Por lo tanto, la equivalencia es, ante todo, un hecho discursivo (Nida 1964, 1969, 1982, 1996; Balliu 2006) que tiene en cuenta el lenguaje "real" que se "utiliza" tanto en la lengua origen como en la lengua meta. 
En cierto sentido, esta idea ya se encontraba en la obra 'behaviorista' (conductual) de Bloomfield (1933), cuando señalaba que el significado de un enunciado lingüístico consistía en la situación en que el emisor lo enunciaba junto a la respuesta-efecto que dicho enunciado provocaba en el receptor. Sin duda, aquí nos estamos adentrando en lo que más adelante se llamaría una perspectiva 'pragmática' del lenguaje, la cuestión de las intenciones comunicativas, de vital importancia en la "interpretación" de los mensajes lingüísticos.

No será, sin embargo, hasta los años 70 cuando el concepto de "equivalencia" adquiera su verdadero giro 'pragmático':

Hubo que esperar hasta la década de los setenta para que se produjera el giro pragmático, que, ligado a la aparición de la lingüística textual y la consideración de los aspectos funcionales sociales y comunicativos del lenguaje, favoreció una visión más holística e interdisciplinar de la traducción, una percepción más crítica y productiva del proceso traductor y sus resultados, y, por ende, impulsó el desarrollo de los Estudios de Traducción como disciplina independiente. (Snell-Hornby 2007:24)

Como ya planteaban Nida \& Taber (1969), la idea de 'comunicación' está por encima de cualquier consideración formal y los 'efectos' que se producen en el receptor del mensaje a partir de este hecho comunicativo (es decir, cómo 'interpreta') se convierten en lo más relevante.

López Folgado (2006:103) relaciona la idea pragmática de la 'intención comunicativa' y los efectos sobre el receptor/interpretante con el concepto de 'contextos social y cultural' en los que el hecho comunicativo se desarrolla:

...[se trata de un] principio pragmático según el cual la elección de las palabras está en función de los contextos sociales y culturales (en definitiva los pertinentes en la mente del receptor), más que de un sistema inmutable y preestablecido de campos semánticos cuyas interrelaciones son per se inamovibles.

Así pues, nuestras elecciones lingüísticas se basan inherentemente en los contextos social y cultural, de ahí la importancia de la relación entre los factores discursivo-textuales y los sociales y culturales.

Por tanto, a la hora de traducir no podemos buscar una equivalencia meramente formal, sino interpretar en base al contexto social y cultural. En palabras de López Folgado (2006:104): "la traducción es, de hecho, un uso interpretativo del lenguaje, más que un ejercicio de equivalencias formales".

Es aquí donde encontramos de suma utilidad el concepto de "equivalencia dinámica" sobre cualquier otro tipo de equivalencia formal, 
bien gramatical o semántica. Nida y Taber (1969: 24) lo definían de la siguiente forma:

Dynamic equivalence is therefore to be defined in terms of the degree to which the receptors of the message in the receptors language respond to it in substantially the same manner as the receptors in the source language. This response can never be identical, for the cultural and historical settings are too different, but there should be a high degree of equivalence of response, or the translation will have failed to accomplish its purpose.

\section{ANÁLISIS DE TEXTOS}

Aplicaremos los conceptos aludidos hasta ahora en dos textos originalmente en inglés, centrándonos en los fallos comunicativos encontrados en sus respectivas traducciones al español.

\section{Texto 1:}

Down and Out in Paris and London by George Orwell, 1933

When we were in the outskirts of Romton, Paddy noticed a bottle of milk on a doorstep, evidently left there by mistake. He stopped, eyeing the bottle hungrily.

"Christ!" he said, "dere's good food goin' to waste. Somebody could knock dat bottle off, eh? Knock it off easy."

I saw that he was thinking of "knocking it off" himself. He looked up and down the street; it was a quiet residential street and there was nobody in sight. Paddy's sickly, chap-fallen face yearned over the milk. Then he turned away, saying gloomily:

"Best leave it. It don't do a man no good to steal. T'ank God, I ain't never stole nothing yet.... It's hell bein' on de road, eh? It breaks yer heart goin' into dem bloody spikes. But what's a man to do else, eh?

I ain't had a good meat meal for about two months, an' me boots is getting bad, an'-Christ! How'd it be if we was to try for a cup o'tay at one o' dem convents on the way to Edbury.

Most times dey're good for a cup o'tay. Ah, what'd a man do widout religion, eh? l've took cups o' tay from de convents, an' de Baptists, an' de Church of England, an' all sorts. I'm a Catholic meself.

Dat's to say, I ain't been to confession for about seventeen years but still I got me religious feelin's, y'understand. An' dem convents is always good for a cup o'tay

Este fragmento de Down and out in Paris and London de George Orwell reproduce el momento en que el autor conoce los barrios bajos de 
Londres de la mano de un mendigo llamado Paddy. Una de las características más llamativas del habla de Paddy es su fuerte acento, vocabulario y gramática irlandesa.

Así, en pronunciación podemos observar:

-d o $t$ en lugar de th: dem (them), t'ank (thanks)

-in' por ing: bein'; o' por of (cup o' tay)

-variación vocálica: yer (you), tay (tea)

En cuanto a los verbos:

-el pasado simple aparece como participio: I ain't never stole nothing ye.t

-falta de concordancia entre sujetos y verbos: it don't do a man no good, we was to try for a cup o' tay.

A continuación contrastamos la traducción llevada a cabo en 1973 para la editorial Destino con nuestra propuesta. Las principales diferencias en la traducción se resaltan en cursiva.

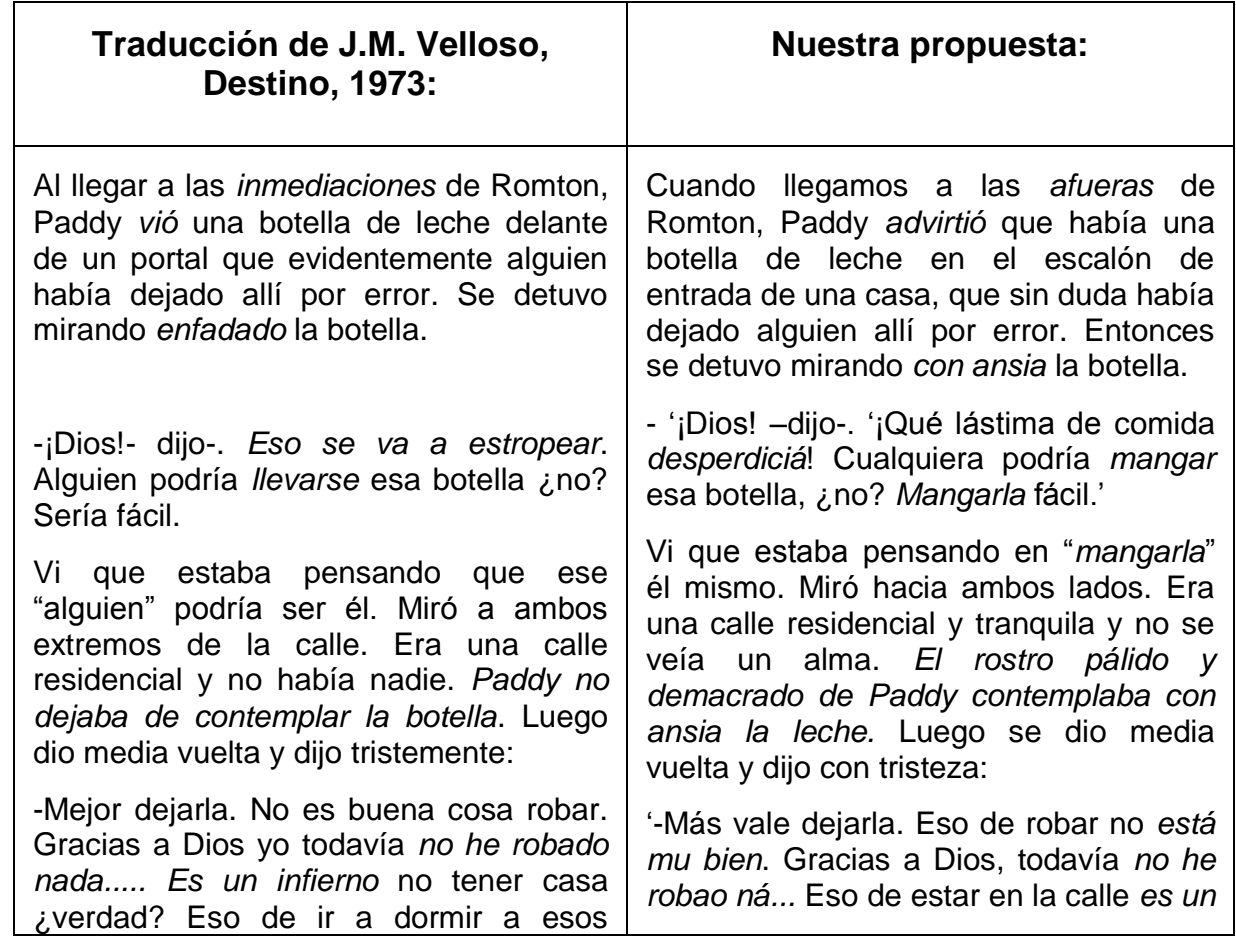


malditos asilos hace polvo a cualquiera. Pero qué remedio hay, si no.

Hace por lo menos dos meses que no sé lo que es comer en serio. Los zapatos se me están rompiendo y.....jDios! ¿qué tal si probaramos a ver si nos dan una taza de té en uno de esos conventos que hay camino de Edbury?

Muchas veces suelen darla. ¡Ah! ¿Qué haría el hombre sin religión? Yo he tomado té en conventos anabaptistas, de la Iglesia de Inglaterra, en todos. Yo soy católico.

Es decir, hace por lo menos diecisiete años que no me confieso, pero sigo siendo religioso. $\mathrm{Ya}$ me entiendes. $\mathrm{Y}$ en los conventos siempre te dan una buena taza de té. asco, ¿no? Es deprimente dormir en esos malditos albergues. Pero, ¿qué otra me queda, no?

Hace por lo menos dos meses que no como un buen guiso, y los zapatos se me están estropeando, y... ¡Dios! ¿y si probamos a ver si nos dan una taza de té en uno de esos conventos camino de Edbury?

Casi siempre te dan una taza de té. Ah, ¿qué sería de nosotros sin la religión, eh? Me he tomao tés en los conventos, en los baptistas, en los anglicanos, en tós ellos. Yo mismo soy católico.

O sea, hace unos diecisiete años que no me confieso, pero aún tengo fe, ¿sabes? $Y$ los conventos son siempre buenos sitios para tomar un té...

Lo más destacable de la traducción en la editorial Destino, 1973, es cómo el traductor ha prescindido de todos los rasgos dialectales o coloquiales y cómo la elección del vocabulario elimina cualquier característica de clase social o procedencia que permitan perfilar el personaje de Paddy y producir una impresión similar en el lector. Evidentemente no se ha profundizado en las características del contexto social o cultural para elaborar la traducción, sino que se ha limitado a una equivalencia formal que deja mucho que desear a la hora de producir los efectos deseados en el interpretante de la lengua meta. Por ejemplo, la traducción de 'knock something off' vendría a ser en español semejante a birlar, mangar. Sin embargo, el aséptico "llevarse" neutraliza cualquier rasgo distintivo del registro coloquial, casi vulgar de Paddy.

Además, una frase tan descriptiva y tragicómica como: 'Paddy's sickly, chap-fallen face yearned over the milk' queda totalmente desvirtuada al traducirse por el simple: 'Paddy no dejaba de contemplar la botella'.

En nuestra propuesta hemos respetado las características del habla del personaje, reproduciendo una gramática incorrecta así como un léxico vulgar, puesto que consideramos que ambos son parte fundamental de la caracterización del personaje. Asimismo, hemos intentado ser fieles a los efectos del texto, si bien para lograrlo hemos tenido que recurrir a una 
variante no estándar del español: "¿Qué lástima de comida desperdiciá! Cualquiera podría mangar esa botella."

Este ejemplo en concreto nos lleva a pensar en el "contexto del proceso de traducción". Se podría aludir a razones sociales, personales o incluso mercantiles para justificar la traducción analizada, carente de toda marca dialectal o de clase social de los personajes. Muy bien podría ser que el traductor o la editorial aplicase un filtro de censura en el lenguaje y la valoración de un lenguaje "correcto" estuviese por encima de un lenguaje "apropiado" para el texto de origen. Asimismo, habría que tener en cuenta que toda desviación de la norma estándar reduce el mercado al que va dirigido el libro. El lenguaje coloquial y vulgar es muy idiosincrático y particular de zonas geográficas reducidas, tanto en el lenguaje original como el de destino. Muchos hispanohablantes no estarían familiarizados con el término "mangar", por ejemplo, y sin embargo no tendrían ningún problema para comprender el término neutro "llevarse" o incluso "robar", que sería más correcto en este contexto. Sea cual sea la razón, lo cierto es que se ha sacrificado la esencia de la caracterización del personaje de Paddy y se le ha desprovisto de toda "personalidad". En cualquier caso, tanto si los fallos pragmático-culturales son debidos a la escasa competencia textual, contextual y cultural del traductor o a la censura o el mercantilismo, la realidad es que la riqueza en matices del producto inicial se ha visto radicalmente mermada.

\section{Texto 2:}

The Meaning of Life, by Monty Python, 1983.

OFFICER: Good morning, Perkins. What's all the trouble then?

PERKINS: Er, been bitten during the night.

OFFICER: Whole leg gone, eh? How's it feel?

PERKINS: Stings a bit.

OFFICER: Well it would, wouldn't it? ... Yes, that's quite a bite you've got there... Any idea how it happened?

PERKINS: Yes, it's a beauty, isn't it? ... No, none whatever. Complete mystery to me. When I woke up just now, one sock too many.

DOCTOR: I came as soon as I could. Is there anything up?

OFFICER: Yes, during the night, Perkins has had his leg bitten, sort of, off.

DOCTOR: Oh, been in the wars, have we? Let's have a look at this one leg of yours, shall we? 


\begin{tabular}{|c|c|}
\hline (Subtítulos) & Nuestra propuesta: \\
\hline $\begin{array}{l}\text {-Buenos días, Perkins. Cuál es el } \\
\text { problema? }\end{array}$ & $\begin{array}{l}\text {-Buenos días, Perkins. (Y bien,) ¿qué le } \\
\text { ha pasado? }\end{array}$ \\
\hline $\begin{array}{l}\text {-Esta noche se me han comido los } \\
\text { mosquitos. }\end{array}$ & $\begin{array}{l}\text {-Pues que me han mordido durante la } \\
\text { noche. }\end{array}$ \\
\hline - ¿Toda la pierna? ¿Te duele? & -Vaya... toda la pierna. ¿Le duele? \\
\hline - Me pica un poco. & -Escuece un poco. \\
\hline $\begin{array}{l}\text {-Es normal... Sí, desde luego se han } \\
\text { ensañado contigo. Alguna idea de cómo } \\
\text { pasó? }\end{array}$ & $\begin{array}{l}\text {-Lógico, ¿verdad? Es que le han dado es } \\
\text { un buen mordisco... ¿Tiene idea de cómo } \\
\text { pasó? }\end{array}$ \\
\hline $\begin{array}{l}\text {-Sí, está preciosa... Ninguna, es un } \\
\text { misterio para mí. Cuando desperté me } \\
\text { sobraba un calcetín. }\end{array}$ & $\begin{array}{l}\text {-Sí, está precioso... No, no tengo ni idea. } \\
\text { Un misterio... Me acabo de despertar y } \\
\text { me sobraba un calcetín. }\end{array}$ \\
\hline $\begin{array}{l}\text {-He venido en cuanto he podido. Ocurre } \\
\text { algo? }\end{array}$ & $\begin{array}{l}\text {-He venido en cuanto he podido. ¿Ha } \\
\text { pasado algo? }\end{array}$ \\
\hline $\begin{array}{l}\text {-Esta noche se le han comido una } \\
\text { pierna a Perkins. }\end{array}$ & $\begin{array}{l}\text {-Sí, esta noche le han } \\
\text { mordido/(arrancado) una pierna a } \\
\text { Perkins... más bien del todo. }\end{array}$ \\
\hline $\begin{array}{l}\text {-Oh, veterano, ¿verdad? ... Echemos un } \\
\text { vistazo a esta pierna. }\end{array}$ & $\begin{array}{l}\text {-Vaya, hemos estado de batallitas, ¿eh? } \\
\text { Vamos a mirar esa piernecita tuya / tu } \\
\text { piernecita... }\end{array}$ \\
\hline
\end{tabular}

En este fragmento de la película de los Monty Python, The Meaning of Life, se reproduce una escena de la batalla entre los zulúes y los británicos en plena guerra de los Boer. Gran parte del efecto humorístico se produce porque el oficial Perkins ha sufrido el ataque de un tigre que le ha arrancado una pierna de un bocado y, sin embargo, lo comenta en clave de humor como si se tratase de algo no muy trascendente. Las imágenes de la película no dejan lugar a dudas y el desarrollo textual del diálogo tampoco. No obstante, en la subtitulación al español de la película se hacen 
elecciones que resultan casi absurdas, al traducir 'bite' no por morder sino por picar.

-that's quite a bite you've got there" $\rightarrow$ desde luego se han ensañado contigo" $\rightarrow$ "Es que le han dado es un buen mordisco"

Por tanto, esta decisión ha afectado, al igual que ocurriera en el texto 1 , las "intenciones" del texto original, mermando el contexto necesario para la total conceptualización del texto en la lengua meta.

\section{CONCLUSIONES}

Es un hecho evidente que la realización lingüística no es uniforme, sino múltiple; de ahí que las elecciones del traductor entre las muchas posibilidades son siempre significativas. En un determinado texto puede destacar la variación lingüística relacionada con un grupo social concreto por su edad, sexo, nivel educativo, sociocultural o por su procedencia geográfica (variación dialectal, como en el caso del texto 1); también la variación puede ser funcional y buscar una interpretación ajustada a un determinado contexto (como la interpretación humorística de las ambigüedades en el texto 2).

El análisis de los dos textos propuestos hace evidente, en primer lugar y de forma muy obvia, que a la hora de traducir no basta con el conocimiento de la lengua origen y de la lengua meta y el establecimiento de equivalencias formales. El proceso de "interpretación" conlleva un conocimiento no sólo de las lenguas 1 y 2 , sino también de los contextos textual (el texto completo), temático (de lo que trata el texto en cuestión), social y cultural. Esta afirmación nos lleva a ser conscientes de la necesidad de un proceso discursivo-pragmático a la hora de traducir.

\section{REFERENCIAS BIBLIOGRÁFICAS}

BALLIU, Ch. "La influencia de Eugene A. Nida en la traductología francófona". En E. ORTEGA, J.P. MONFERRER y V. LóPEZ (eds.), Eugene A. Nida, pionero de la traductología contemporánea. Granada: Atrio, 2006. Pp. 77-97.

BASSNETT, S. "The Translation Turn in Cultural Studies". En S. BASSNETT y A. Lefevere (eds.), Constructing Cultures. Clevedon/Filadelfia. Multilingual Matters, 1998. Pp. 123-140.

BLOOMFIELD, L. Language. Londres: Allen \& Unwin. 1933. [1965]

CÁmARA, E. y Kelly, D. Discurso, texto y traducción. Granada: Grupo Avanti. 2005.

CARBonelL, O. Traducción y cultura. De la ideología al texto. Salamanca: Ediciones Colegio de España. 1999. 
HATIM, B. y MASON, I. Teoría de la traducción: una aproximación al discurso. Barcelona: Ariel. 1995.

LÓPEZ FolgADO, V. "La influencia de Eugene A. Nida en la traductología anglófona. Eugene A. Nida: La búsqueda de la solución al desacuerdo entre intenciones y expectativas en la traducción". En E. ORTEGA, J.P. MONFERRER y V. LóPEZ (eds.), Eugene A. Nida, pionero de la traductología contemporánea. Granada: Atrio, 2006. Pp. 97-110.

y BADDER, D. Translation in Action. Córdoba: Servicio de Publicaciones de la Universidad de Córdoba. 1999.

NIDA, E.A. Toward a Science of Translating. With Special Reference to Principles and Procedures Involved in Bible Translating. Leiden: E.J. Brill. 1964. 1982.

Translating Meaning. San Dimas, CA: English Language Institute.

The Sociolinguistics of Interlingual Communication. Bruselas : Les Éditions du Hazard. 1966. 1969

y TABER, C. The Theory and Practice of Translation. Leiden: E.J. Brill.

PyM, A. Translation and Text Transfer. An Essay on the Principles of Intercultural Communication. Frankfurt: Peter Lang. 1992.

SALVADOR, V. "Pragmatics and stylistics" [en línea], Noves SL. Revista de Sociolingüística. Disponible en: <http://www.gencat.cat/lengua/noves>

SCHULTE, R. "Translation Theory: A Challenge for the Future", Translation Review, no 23, (Special Theory Issue). 1987.

SNELL-HORNBY, M. "Haz un diálogo y no la guerra: el estado actual de los Estudios de Traducción". En ORTEGa ARJONILLA (ed.) El Giro Cultural de la Traducción. Frankfurt: Peter Lang. 2007.

VAN DIJK, T. Discourse Studies. A Multidisciplinary Introduction. Londres: Sage. 1997.

VENUTI, L. The Scandals of Translation. Londres y Nueva York: Routledge. 1998.

VINAY, J.P. y J. DARBELNET. Stylistique comparée du français et de l'anglais. París: Didier. 1958. 